\title{
The Role of Group Sharing Model in Creating Effective and Fun Learning
}

\author{
${ }^{1}$ Sudirman \\ \{*sudirman@ung.ac.id\} \\ ${ }^{1}$ Department of Economics Education, Universitas Negeri Gorontalo, Gorontalo, Indonesia
}

\begin{abstract}
Students expect an attractive and fun learning to motivate and to help them understand the lesson. Teachers, as the ones who manage a learning activity, have designed group sharing model that can promote an interesting and engaging learning. This paper explores the issue regarding the role of group sharing learning model in promoting a fun and effective learning. The purpose of the current study is to describe the role of the learning model in achieving its targets. It can be inferred that the group sharing learning model is able to have the students engaged in the activity because the model allows them to be creative in developing their competence. Furthermore, this effective learning integrates the concepts from each member of a group based on the focus of the lesson.
\end{abstract}

Keywords: Group Sharing, Learning, Effective, Fun.

\section{Introduction}

Many students [1];[2];[3] expect attractive, effective and fun learning by which such learning can help them to pay attention to the class. It also psychologically promote a comfortable situation for teachers in transferring the knowledge to their students. Therefore, the learning objectives can be achieved through implementation of learning model.

Learning model [4][5] refers to a learning method implemented by the teachers to create effective and attractive learning for students. It also helps the teachers to disseminate the knowledge to their students in understanding a particular lesson. The success of the implementation depends on the teachers' competence in designing a learning model based on the proposed guideline.

Furthermore, a learning model aims at promoting engaging and effective learning to improve students' academic achievement. They will be guided to develop their selfcompetence through their works in a real-time situation. This will alleviate their problems during the learning.

Teachers[6] are responsible for developing an effective and engaging learning which is expected by those who concern with the issue of education, e.g., students, parents, as well as the society. Parents play [7] a significant role in improving students' academic achievement whereas the society is responsible for enhancing the students' capacity. By that, teachers are expected to promote an attractive and effective learning atmosphere. The implementation of group sharing learning model is, therefore, expected by the learners in participating in effective and fun learning; the process is implemented without having the students feel being 
forced to learn. Still, the situation enables the students to focus on the lesson to achieve the indicators of the learning.

\section{Methodology}

\subsection{Group Sharing}

Group Sharing[8][9] is a learning model that gives the students the freedom to improvise and to be creative in the process of learning. It also enables the students to produce something as a result of their learning; the result will be presented to other students in a group by visiting one booth (the groups will work in some booth) to another.

The term learning model refers to a systematic procedure in formulating a learning objective. This term shares some similarities with strategy, method, and learning approach. Recently, there has been a number of learning models developed that range from the simple to the complex one due to the instruments needed in its implementation. Therefore, a teacher is required to possess teaching competence to motivate his or her students, to design an instructional model, to manage the class, to communicate and plan the learning, and to conduct an effective evaluation [10].

Group sharing is a learning model which allows the students to develop their competence on their own through producing their works based on the designed materials. The implementation of this learning method aims at promoting an effective learning. Furthermore, Griffiths (2015) adds several characteristics of an effective learning, such as transformative, active, interactive, intrinsically motivating, and life-long.

According to Kizkapan et al (2017), project-based learning model is unable to enhance students' academic achievement significantly. This is due to the fact that most students are adjusted with the traditional learning model in which the teacher is the center of the learning. As a result, such a teacher-centered approach constraints the implementation of group sharing model. Thomas (as cited in [11]) argues that curriculum is essential in implementing a learning model-it serves as the guideline of the model.

According to Janaikova and Janaik (2017), the development of natural science results in a condition by which the students will be more likely to discover a particular process. In other words, this is considered as demand for young students. They are expected to possess abstraction skill and the ability to comprehend a correlation between the model and the most frequent reality. Consequently, this will guide the students to recognize the reality.

An innovative learning creates another challenge in understanding the implementation of the technology development in a learning model. Without a clear concept regarding the complexity and the development of the role of technology, it is difficult to examine the advantages of the use of technology and media in the learning model to enhance the learning activity [12].

Therefore, the success of the implementation of group sharing model lies in the teachers' effort to create an attractive and efficient learning situation as well as to reach the target proposed in the curriculum.

Group sharing is a learning model which involves a number of groups of students to discuss and create a work regarding the lesson in the form of a picture or description; the product from each group will be displayed on a post-it. There will be a representative of each group who is responsible for describing their work every time other groups visit their post-it. The way the representative explain the details will be assessed by the other. 
This model[10]-[14] is able to engage all students throughout the learning because of the different jobs that have been distributed to all members of each group. As a result, students are aware of their job even though it is somewhat a simple task. Students will focus on the learning because they are required to achieve the target.

\section{Result and Discussion}

\subsection{Defining Effective Learning}

Effective learning refers to a process of teaching and learning that enable the learners to learn more specific skills, knowledge, and attitude. This kind of learning also creates an atmosphere by which the students enjoy the class.

Several components, e.g., developing one's knowledge gradually, discovery-oriented knowledge rather than memory-oriented, questioning, community learning, modeling, reflection, and authentic assessment are involved in an effective learning [13].

According to Topala (2014), an effective learning refers to a situation of achieving high performance with the lowest cost. Topala further explains that a positive appeal during the learning process results in a situation to work, ensuring the involvement of an active individual in learning. This effective learner's responsibilities are to form information, policy, and ideas from his or her teacher through an effective use of learning resources [14].

The tenet of effective learning is to reach targets of the learning process rather than to produce something related to the skills that the students should master after the learning activity [9].

\subsection{Defining Fun Learning}

Fun learning is among things that students expect in the class. Therefore, it is the main duty of a teacher to design learning that could motivate the students to be creative and active as it can eliminate boredom during the learning. This is in line with Zinn's argument that developing students' capacity to think creatively and critically through fun but serious learning [9].

Designing a fun learning is not that difficult for teachers since they can utilize some media to support them in their practice. The rapid pace of technology development will help them during the implementation of a particular learning model in motivating the students. According to Saeedeh, Michele, Mo and Nina (2015), a project-based learning model that integrates some aspects of designing, science, and technology is effective to raise students' enthusiasm and participation.

Fun learning contributes to the students' learning outcome. According to Packer and Ballantyne (as cited [8]), both the aspect of fun and entertainment is related to an idea that an enjoyable situation is a key to a successful learning based on the students' perspective. Therefore, the group sharing model offers a learning that can create such a condition in promoting students' curiosity regarding a particular lesson. Boddy, Watson and Aubusson (2003) add that motivation can lead the students to learn and vice versa. Motivation and learning are interdependent; both are supporting each other.

Fun learning also creates an attractive learning situation that can eliminate boredom and enable the students to focus on the lesson [14]. In other words, a fun learning refers to a process of learning that can motivate the students and improve their concentration during the class. 
Mildner, Beck, Reinsch and Effelsberg (2016) argue that the key aspect of this learning is to integrate games into the activity which results in an enjoyable and effective learning. Such a game can be regarded as the part of the learning process; it is inseparable from the learning. Moreover, one may change the game used in a specific lesson.

\section{Conclusion}

The results reveal that the implementation of group sharing model is able to create an effective and fun learning compared to other learning models. This is based on the students' engagement and participation during the class. Furthermore, teachers' competence is the contributing factor of the success of the implementation of group sharing model. Teachers are required to master the model as well as to comprehend the students' characteristics; this is to motivate and guide the students. An effective learning is a condition to accomplish targets in a set of time frame regardless of the efforts that have been attempted. On the other hand, fun learning refers to an enjoyable learning situation for the students that can eliminate their boredom during the class. This raises their motivation and curiosity to learn

\section{References}

[1] Boddy, N. Watson, K. and Aubusson, P. (2003). A Trial of the Five Es: A Referent Model for Constructivist Teaching and Learning. Netherlands: Kluwer Academic Publishers.

[2] Budimansyah, D. and Suparlan, D.M. (2009). PAKEM: Pembelajaran Aktif, Kreatif, Efektif, dan Menyenangkan [PAKEM: Active, Creative, Effective, and Fun Learning]. Bandung: Genesindo.

[3] Christine M. and Van Winkle. (2014). The Effects of Entertainment and Fun on the Visitor's Free-Choice Learning Experience. Journal of Leisure Research, 46(5).

[4] Caird, S. and Lane, A. (2015). Conceptualising the role of information and communication technologies in the design of higher education teaching models used in the UK. British Journal of Educational Technology, 46(1).

[5] Colin, M. (1996). Handbook for beginning teachers. Sydney: Addison Wesley Longman Australia Pry Limited.

[6] Gogus, A. Gogus. and Nihat, G. (2011). Understanding the Effective Learning Habits of the Generation Y, Proceedings of the IADIS International Conference on Cognition \& Exploratory Learning in Digital Age. pp. 271-274.

[7] Joyce, B. and Well, M. (1996). Models of Teaching. London: Allyn Bacon.

[8] Kateina, J. and Antonin, J. (2017). Teaching Aids and Work with Models in e-Learning Environments. The Electronic Journal of e-Learning, 15(3).

[9] Kerryn, G. (2015). Personal Coaching: A model for Effective Learning. Journal of Learning Design. 8(3).

[10] Mildner, P. Beck, O. Reinsch, M. and Effelsberg, W. (2016). The Influence of Learning and Gaming Coherence on the Effectiveness of Serious Games, Proceedings of the European Conference on Games Based Learning, 1.

[11] Oktay, K. and Oktay, B. (2017). The Effect of Project Based Learning on Seventh Grade Students' Academic Achievement. International Journal of Instruction January 2017, 10(1).

[12] Saeedeh, Z. Michele, H.M. Mo, R. and Nina, M._ (2017). Co-robotics hands-on activities: A gateway to engineering design and STEM learning. Robotics \& Autonomous Systems, 97.

[13] Topala, I. (2014). Effective Learning And Learning Satisfaction, In An Academic ContextDiscussion Concerning An Integrating Model. Journal Plus Education, pp. 2068 - 1151. 
[14] Zinn, Wilkins-0'Riley. (2008). Making Fun of School, or Why does Learning have to be Such a Drag? Six Key Elements for Motivating Learning. The International Journal of Learning, 15(8), pp. 1447-9494. 